\title{
PERCEPCÃO DO SISTEMA DE GESTÃo AMBIENTAL PELOS FUNCIONÁRIOS DA ESTAÇÃO DE TRATAMENTO DE ÁGUA DA COMPANHIA DE ÁGUA E ESGOTO DO CEARÁ
}

\author{
GERNANDA RODRIGUES RODRIGUES DE OLIVEIRA \\ ${ }^{1}$ Instituto Federal de Educação, Ciência e Tecnologia do Ceará (IFCE) \\ <gernanda.ro@gmail.com>
}

DOI: $10.21439 /$ conexoes.v11i6.1140

\begin{abstract}
Resumo. O presente trabalho tem como objetivo avaliar a percepção ambiental dos funcionários da Estação de Tratamento de Água da Companhia de Água e Esgoto do Ceará - CAGECE, com a finalidade decontribuir para melhorar o sistema de gestão ambiental da instituição supracitada, além de incentivar futuros trabalhos sobre o tema. A coleta de dados foi realizada através da aplicação de questionários, via e-mail e impressos, aos empregados da empresa que trabalham na área onde o programa foi implantado. Os resultados mostraram a importância da implantação do sistema de gestão ambiental, baseado na Norma ISO 14001, no desenvolvimento de mudanças de atitudes e de valores, transformando os funcionários em cidadãos conscientes e críticos em relação ao meio ambiente. Concluiu-se que o sistema de gestão ambiental possui um papel fundamental no desenvolvimento da consciência ambiental e nas atitudes dos empregados, dentro e fora da empresa. Entretanto, apesar da colaboração positiva, o programa precisa ganhar mais força e evidência visando alcançar os objetivos definidos em sua política.
\end{abstract}

Palavras-chaves: Gestão Ambiental, Percepção Ambiental, ISO 14001.

\begin{abstract}
This study aims to evaluate the environmental awareness of employees of water treatment station of Companhia de Água e Esgoto do Ceará-CAGECE, in order to contribute to improving the environmental management system of the aforementioned institution, and stimulate other works about the subject. Data collection was conducted through questionnaires, via $e$-mail and printed, to company employees working in the area where the program was implemented. The results showed the importance of the environmental management system implementation, based on ISO 14001, in the change in attitudes and values, turning employees into conscious citizens and critical of the environment. It was concluded that the environmental management system has an important role in the development of environmental awareness and attitudes of employees within and outside the company. However, despite the positive collaboration, the program needs to gain more strength and evidence aimed at achieving the objectives defined in your policy.
\end{abstract}

Keywords: Environmental Management, Environmental Awareness, ISO 14001.

\section{INTRODUÇÃO}

O processo da industrialização no mundo resultou em uma intensa exploração dos recursos naturais. O desenvolvimento econômico juntamente com o crescimento populacional fez com que os problemas ambientais aumentassem gerando vários efeitos negativos à natureza e ao próprio ser humano. A partir disso, o homem percebeu que os recursos naturais não eram inesgotáveis, ou seja, com a consciência ambiental é que se observou maior preocupação com as questões ambientais (CONCEIÇÃO et al., 2011).

A correta gestão da água é de extrema importância para sua proteção, produção, tratamento e distribuiçãoe essa gestão não envolve apenas aspectos operacionais, mas também o envolvimento geral da organização, a diminuição dos impactos ambientais, o gerenciamento 
dos recursos naturais, ou seja, um modelo de gestão que não vise apenas o lucro, mas principalmente a proteção do meio ambiente. Nas grandes empresas, a gestão ambiental passou a ser uma atividade essencial para a melhoria contínua dos processos e procedimentos, principalmente em se tratando daquelas empresas que possuem como missão levar um recurso essencial à vida da população, como a água (SOUZA et al., 2009).

O Sistema de Gestão Ambiental - SGA é a parte de um sistema da gestão utilizado pelas empresas para elaborar e efetivar sua política ambiental e para coordenar seus aspectos ambientais, incluindo estrutura organizacional, atividades de planejamento, responsabilidades, práticas, procedimentos, processos e recursos (ISO 14001, 2004). Atualmente o SGA, juntamente com a norma ISO 14001, forma a opção mais utilizada pelas empresas para realizarem suas atividades, reduzindo os custos, melhorando o processo produtivo sem deixar de lado o cuidado com o meio ambiente.

A adoção do SGA contribui para diminuir as infrações, melhorar a eficiência operacional, evitar a poluição, reduzir o desperdício, e diminuir a quantidade de resíduos, gerando mais economia para a empresa. A norma ISO 14001 antecipa maneiras de como monitorar e cumprir as normas e dar assistência no treinamento dos funcionários com relação à sua contribuição na melhoria e na proteção do meio ambiente (CORREIA, 2006). No entanto, o desenvolvimento e implantação do SGA têm encontrado diversas barreiras, dentre elas, a falta de interesse por parte da administração, a dificuldade em compreender os procedimentos, e principalmente a ausência de treinamento e a rejeição as alterações nos hábitos. O processo de implantação exige mudanças na cultura e na estrutura das organizações e principalmente o envolvimento dos gestores e colaboradores (OLIVEIRA; PINHEIRO, 2010).

Nenhum processo ocorre sem que haja mudançase a gestão ambiental envolve a modificação entre a sociedade e o meio ambiente. Essa mudança, tanto organizacional como cultural, é o que mais dificulta na introdução de um sistema de gestão ambiental. Para que os benefícios do programa sejam alcançados diversos fatores são essenciais, como o comprometimento da alta direção, gestão da mudança, o envolvimento dos empregados e, consequentemente, a forma como foram motivados para isto. Assim, justifica-se o desenvolvimento desse trabalho, cujo objetivo está em avaliar a percepção do Sistema de Gestão Ambiental pelos funcionários da Companhia de Água e Esgoto do Ceará, assim como avaliar as mudanças nas ações diárias dos funcionários em relação ao meio ambiente.

\section{FUNDAMENTAÇÃO TEÓRICA}

\subsection{Gestão Ambiental e a ISO 14001}

A gestão do meio ambiente tem como objetivo manter ou melhorar as condições de vida das pessoas sem causar danos ao meio ambiente, diminuindo os impactos negativos causados pela intervenção e implantação de projetos ou atividades. Nos países em desenvolvimento como o Brasil, cresce cada vez mais o interesse e o envolvimento nas questões relacionadas ao meio ambiente, sendo os elementos ambientais priorizados na avaliação e construção de projetos (CORREIA, 2006).

Segundo Cagnin (2000), a relação entre o meio ambiente e o desenvolvimento econômico passou a ser uma associação entre o crescimento econômico e a preservação dos recursos naturais saindo do âmbito exclusivo dos ecologistas e ganhando uma atenção maior da sociedade em geral. Para muitas empresas o cuidado com o meio ambiente e a preocupação em reduzir os impactos gerados leva a melhoria da sua imagem no mercado, passando a ser um fator estratégico de competitividade, sendo de fundamental importância incorporar a gestão ambiental ao sistema de gerenciamento (MOREIRA, 2004).

Trabalhar de acordo com as leis ambientais, se responsabilizar financeiramente pelos danos ambientais, mudar a imagem da empresa observando as novas exigências dos consumidores são alguns desafios das indústrias para cumprir seu compromisso com o meio ambiente (DELMAGRO; OTT, 2002).O Sistema de Gestão Ambiental - SGA é definido como parte do sistema de gestão que inclui estrutura organizacional, atividades de planejamento, responsabilidades, práticas, procedimentos, processos e recursos para desenvolver, implantar, analisar e manter a política ambiental. (NBR ISO, 2004).

Para Moreira (2006), o sistema de gestão ambiental é o conjunto dos elementos da organização que visa à implantação da política ambiental da empresa. Sendo o Sistema de Gestão Ambiental incorporado à estrutura organizacional da empresa com o fim de conhecer, prever e amenizar os impactos ambientais gerados em consequência das suas atividades, produtos e serviços. A implantação de um SGA baseado na ISO 14001, por uma organização, pode ser vista como uma modernização, pelo fato do processo exigir uma mudança comportamental e organizacional. As características e culturas da empresa devem ser ajustadas, considerando os objetivos a serem alcançados com a introdução do sistema (CAGNIN, 2000). A figura 1 ilustra os princípios do sistema de gestão ambiental: 


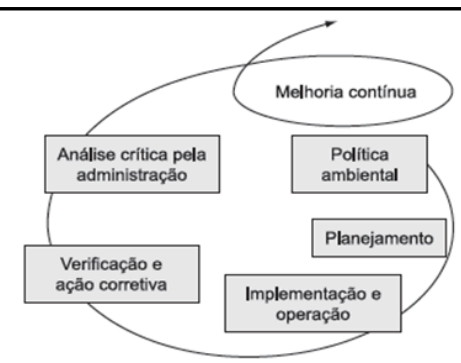

Figura 1: Espiral do sistema de gestão ambiental. Fonte: ISO 14001 (2004).

Os princípios para implantação do SGA, segundo Lima e Lira, (2007) são:

I. Política ambiental: é necessário que a empresa defina seu modelo de organização e garanta o compromisso com o sistema de gestão ambiental. A política ambiental é definida pela alta direção e deve ser divulgada pra toda organização, consumidores, fornecedores e comunidade.

II. Planejamento: a empresa precisar ter uma estratégia para efetivar sua política, ela deve criar condições a fim de efetuar a política ambiental adotada pela organização.

III. Implementação e operação: caracterizada pela execução do que foi programado na fase de planejamento, realização de treinamentos e determinação dos meios exigidos para atender a política.

IV. Verificação e ação corretiva: Esse item serve para verificar se a empresa está cumprindo com os itens que o programa determina, através do acompanhamento, identificação de irregularidades, ações de correção e de prevenção, controle e registro das informações e realização de auditorias.

V. Análise crítica pela administração: A administração vai avaliar a necessidade de alterar os objetivos, metas da política ambiental ou outros itens do sistema de gestão ambiental. Com o cumprimento de todas essas etapas, começa um novo ciclo buscando o aperfeiçoamento das responsabilidades e do desempenho ambiental através da melhoria continua dos processos

O Quadro 1 mostra as etapas da fase de implantação do SGA:

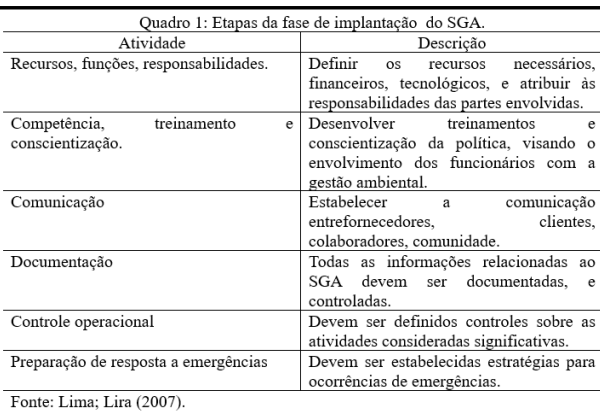

\subsection{Percepção Ambiental}

O planeta sofre com inúmeras dificuldades ambientais e a falta de consciência de alguns seres humanos agrava esses problemas em todo mundo. No entanto, parte da população vem tentando interligar o seu estilo de vida com o meio ambiente, procurando se envolver e estudá-lo de forma mais aprofundada, buscando minimizar os impactos negativos de suas atividades com uma maior conscientização e proteção do ambiente ao seu redor (VICENTE, 2008).

A percepção ambiental objetiva estudar o comportamento do homem diante do meio ambiente, ela está ligada à ação do homem sobre o meio e do modo como ele percebe o ambiente em que está introduzido aprendendo a cuidar e protegê-lo. Essa compreensão pode ser definida ainda como o entendimento e sistematização de dados recebidos para o desenvolvimento da conscientização do ambiente que nos cerca. A percepção de algo significa a sua interpretação (BARTHOLOMEU FILHO et al., 2014).

A percepção se refere à relação mútua entre homem e o meio que o cerca. Segundo Vicente (2008), para que possamos realmente perceber é preciso um interesse no elemento a ser percebido e isso é baseado no conhecimento, na cultura, na ética, e na atitude de cada pessoa, gerando assim percepções diferentes em cada indivíduo. Para este autor, cada pessoa age de forma diferente, suas ações são resultado da sua percepçãoe tratando-se de meio ambiente são diversos os aspectos que afetam a maioria dos indivíduos, direta ou indiretamente. Para saber como as pessoas percebem o meio em que vivem, é essencial a realização de pesquisas que abordem a percepção ambiental.

\subsection{Sistema de gestão ambiental na CAGECE}

A Companhia de Água e Esgoto do Ceará - CAGECE nasceu através da Lei ${ }^{\circ} 9.499$, de 20 de Julho de 1971, com o objetivo de trazer a todo estado serviços abastecimento de água e esgotamento sanitá- 
PERCEPÇÃO DO SISTEMA DE GESTÃO AMBIENTAL PELOS FUNCIONÁRIOS DA ESTAÇÃO DE TRATAMENTO DE ÁGUA DA COMPANHIA DE ÁGUA E ESGOTO DO CEARÁ

rio (SOUZA et al., 2009). Neste mesmo ano criou-se também o Plano Nacional de Saneamento - PLANASA, que tinha como intuito solucionar os problemas de saneamento básico no Brasil. Segundo o IBGE no ano de 1985, quinze anos após sua aplicação, o PLANASA assinalava $87 \%$ da população urbana abastecida com água potável (MONTEIRO, 1993). Hoje a CAGECE tua em 151 municípios no Ceará, com índice de cobertura de abastecimento de água de $98,14 \%$ e de esgotamento sanitário 40,09\%. (CAGECE, 2015).

A estação de tratamento de água foi construída em 1981 no município de Pacatuba, a 34 km de Fortaleza. A ETA fica próxima ao açude Gavião (Imagem 1) que foi construído para complementar, juntamente com os açudes Pacoti e Riachão,a rede de água potável, formando a principal fonte de abastecimento de Fortaleza e Região Metropolitana (CAGECE, 2011). A ETA tem a finalidade de tratar água, tornando-a potável para distribuição e consumo, respeitando as exigências descritas na portaria 2914/2011 do Ministério da Saúde(BRASIL, 2011). Todas as etapas de produção da água exigem o monitoramento da qualidade a fim de não oferecer riscos à saúde da população. Buscando fortalecer as ações voltadas para alcançar a melhoria continua da qualidade dos serviços prestados a CAGECE iniciou em 1996 o programa de gestão da qualidade, tendo como referência a Norma NBR ISO 9001 (CAGECE, 2011). Para o desenvolvimento desse programa foi criada a política da qualidade (CAGECE, 2011), onde foram definidos os objetivos da qualidade que abrange todas as funções da empresa em todas as áreas de atuação.

A política de qualidade da CAGECE tem como princípios o fornecimento de água potável e a realização do tratamento de efluentes de acordo com os requisitos regulamentares, assim como promover a melhoria contínua do sistema de gestão para aumentar a satisfação dos clientes. Em conjunto com o sistema de gestão da qualidade e, procurando adaptar suas atividades com a proteção do meio ambiente, a CAGECE começou em 2005, a introdução do sistema de gestão ambiental na estação de tratamento de água. Dentre os principais benefícios do sistema (CAGECE, 2014), estão:

- A uniformização das tarefas e de processos, reduzindo acidentes e melhorando a segurança;

- cumprimento das leis, reduzindo e prevenindo multas;

- A melhoria da imagem da empresa junto à sociedade;
- Controle da poluição e do lançamento de efluentes controlando e minimizando os impactos ambientais negativos;

- Diminuir o uso dos recursos naturais (água energia, matérias-primas e insumos), evitando desperdícios e reduzindo custos, reutilizando os materiais reutilizáveis.

\section{METODOLOGIA}

O presente trabalho traz um estudo sobre o sistema de gestão ambiental e sua percepção pelos funcionários na Estação de Tratamento de Água da Companhia de Água e Esgoto do Ceará.

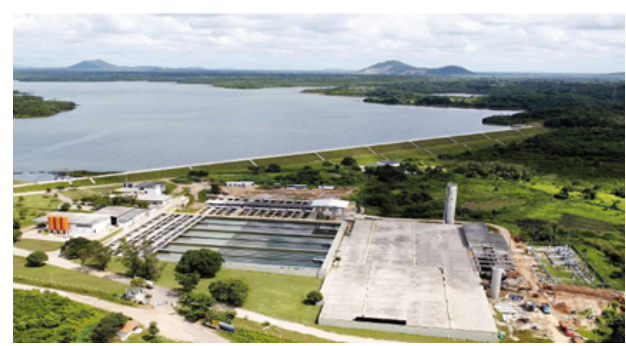

Figura 2: Foto aérea da Estação de Tratamento de Água da CAGECE, localizada no município de Pacatuba-CE. Fonte: Informativo da Companhia de Água e Esgoto do Ceará (2013).

Para sua realização, foi elaborado um levantamento bibliográfico sobre o tema tendo como embasamento teórico a leitura de monografias, teses, dissertações, artigos e publicações. Além disso, consultas a documentos e textos contidos nos arquivos da empresa foram realizados para melhor entendimento e análise dos dados pesquisados. Essa pesquisa classifica-se como exploratório-descritiva, que para Marconi e Lakartos (2003), são pesquisas cujo objetivo é a formulação de uma questão ou problema com a finalidade de aumentar o conhecimento do pesquisador descrevendo completamente o ambiente, fato ou fenômeno. Ainda segundo os autores, a pesquisa descritivaobserva, registra, analisa e ordena os dados sem interferir utilizando-se de técnicas específicas tais como entrevista, questionário, formulário, teste e observação.

A obtenção de dados relacionados à percepção dos servidores envolvidos na ETA Gavião e que trabalham diretamente com a aplicação do SGA da empresa, foi feita através da aplicação de questionário (anexo 1) com afirmativas relacionadas ao conhecimento dos funcionários quanto ao sistema de gestão ambiental implantado na empresa e como a implantação dessa prática influenciou nas atitudes das pessoas em relação ao meio 

COMPANHIA DE ÁGUA E ESGOTO DO CEARÁ

ambiente dentro e fora da empresa. Os questionários foram enviados parte via e-mail e parte foi impressa para funcionários que trabalham na unidade operacional e não possuem acesso ao correio eletrônico da companhia. A ETA possui 48 funcionários entre administrativos, auxiliares de manutenção e operação, motoristas, técnicos operacionais e de laboratório. Ao todo foram respondidos 21 questionários correspondendo a $43 \%$ do total.

\section{RESULTADOS E DISCUSSÃo}

A pesquisa foi feita através da aplicação de questionários contendo afirmativas no qual os funcionários deveriam,de acordo com o seu entendimento, discordar totalmente, discordar parcialmente, ser indiferente, concordar parcialmente ou concordar totalmente sobre a sua percepção em relação ao sistema de gestão ambiental. Na distribuição dos funcionários por cargo observou-se que a maioria dos funcionários trabalha no setor operacional e de manutenção da ETA, entre eles: operador de elevatória, auxiliar de operação e supervisor de produção, representando 53\% dos entrevistados, sendo a maior parte $(80 \%)$ dos funcionários participantes do sexo masculino. A média de tempo de serviço na empresa é de cinco anos, sabendo-se que o programa começou a ser implantado em 2005, considera-se que a maioria dos funcionários já possui um bom tempo de convívio com as ações relacionadas à gestão ambiental.

Em relação à escolaridade, $9 \%$ possuem apenas o nível fundamental, $52 \%$ possuem o ensino médio completo, $26 \%$ dos funcionários concluíram o ensino superior, além de $13 \%$ possuírem formação técnica. Quanto à política ambiental, 43\% dos funcionários afirmaram conhecer a política da empresa, totalmente ou parcialmente, $9 \%$ discordaram parcialmente da afirmativa e apenas $5 \%$ disseram ser indiferente ao conhecimento sobre a política. A NBR ISO 14001 coloca como requisito geral para implantação do SGA a definição da política ambiental, assim como a sua divulgação para todos que trabalham na empresa e para o público. A política deve ser documentada, implantada e mantida.

$\mathrm{Na}$ CAGECE, $43 \%$ dos funcionários responderam que a política ambiental é bem divulgada para funcionários e cliente, $38 \%$ responderam que a política é parcialmente divulgada e $14 \%$ se mostraram indiferentes. A divulgação da política é feita através de banners expostos nas unidades, quadros de aviso, boletins informativos e também disponível no site da companhia. Entende-se com isso que de fato há divulgação da política, porém a ausência de conhecimento por parte de um número significativo de funcionários se deve à falta de sensibilidade ao tema e isso deve ser solucionado por meio de mais momentos presenciais onde os gestores precisam elucidar quanto à importância do conhecimento da política ambiental por parte dos funcionários.

Dos participantes, $52 \%$ disseram já ter participado de treinamentos, curso, palestra ou possuir algum conhecimento sobre o sistema de gestão ambiental. No entanto, os 14\% discordaram totalmente da afirmativa, significando que não participaram de nenhum treinamento referente ao SGA. Segundo Correia (2006) o treinamento é um processo importante para impulsionar a mudança, sendo esta um meio de estimular as pessoas a alterar seus valores, crenças, hábitos e interesses comuns. Todos os funcionários da empresa devem ser conscientes do sistema de gestão ambiental, principalmente os que fazem atividades potencialmente poluidoras. A conscientização, conhecimento e competência devem ser obtidos através de treinamentos, instrução ou prática de trabalho, cabendo à organização identificar as habilidades necessárias a qualquer indivíduo que desempenhe qualquer atividade em seu nome (NBR ISO 14001, 2004).

Quanto à coleta seletiva da empresa, 90\% dos participantes afirmaram que colaboravam com o programa, enquanto que $5 \%$ se mostraram indiferentee outros $5 \%$ não colaboravam com o programa. A coleta seletiva teve início na CAGECE em 2004 com a distribuição de coletores de material reciclável, seguindo o critério das cores para facilitar a separação, com o intuito de preservar o meio ambiente da possível poluição causada pela má disposição do lixo. (CAGECE, 2011).

Correia (2006) coloca algumas perspectivas que correspondem às formas de mudanças organizacionais que ocorrem nas empresas e uma delas é a perspectiva humana, onde o foco está na ligação do indivíduo com o trabalho e para que ocorra essa mudança é necessário à transformação de atitudes, comportamentos e a forma de participação das pessoas. Fora da empresa $43 \%$ dos funcionários afirmaram que suas ações são influenciadas pela política ambiental estabelecida dentro da empresa.

Verificou-se que um percentual elevado de funcionários (86\%) incentivam suas famílias a reduzir os gastos com água e energia em casa, no entanto uma porcentagem menor foi observada em relação à preocupação com o lixo, 65\% disseram fazer a separação do lixo reciclável do não reciclável em suas residências, porém $20 \%$ afirmaram ser indiferente a separação do lixo e $15 \%$ disseram não fazer essa separação. Na compra de algum produto, 33\% afirmaram preferir os que são feitos de material reciclável, como vidro, alumínio ou 
PERCEPÇÃO DO SISTEMA DE GESTÃO AMBIENTAL PELOS FUNCIONÁRIOS DA ESTAÇÃO DE TRATAMENTO DE ÁGUA DA COMPANHIA DE ÁGUA E ESGOTO DO CEARÁ

mesmo produtos com refil. $43 \%$ dos participantes levam em consideração a certificação ISO 14001 na compra de algum produto ou serviço.

Observa-se que os melhores desempenhos ou mesmo envolvimento estão associados aos serviços que implicam nos gastos financeiros pelo consumidor, (exe: água e energia), já nos serviços de coleta de lixo, como não há um motivador econômico a sensibilização é enfraquecida. Dessa maneira, entende-se que não há uma maior preocupação em relação à separação do lixo, pois isto não irá contribuir em nada com a redução das despesas familiares. Necessita-se, neste caso, uma maior sensibilização quanto aos ganhos ambientais obtidos por estas ações e não apenas ganhos financeiros. É possível perceber que a gestão ambiental proporciona não só a obtenção de conhecimento, mas o desenvolvimento de atividades que proporcione o conhecimento, reflexões e atitudes com relação ao meio ambiente.

Uma das finalidades da implantação de um sistema de gestão ambiental é igualar proteção e prevenção da poluição com as necessidades econômicas. Dos funcionários respondentes, $71 \%$ afirmaram que a implantação do SGA contribui na redução da poluição na CAGECE e esse mesmo porcentual afirmou que houve uma melhoria nos serviços prestados pela empresa. A prevenção da poluição inclui a redução das fontes de poluição, o controle do lançamento de efluentes no ambiente, o uso eficiente dos recursos naturais como água e energia e a reutilização, recuperação e reciclagem de materiais e produtos, gerando assim mais economia e evitando o despedício. Praticamente a totalidade dos funcionários $(90 \%)$ acreditam que é sua responsabilidade ajudar a melhorar a qualidade ambiental dentro e fora da empresa. Esses resultados mostram que os funcionários já estão de alguma maneira envolvidos com o SGA e essa aceitação é fundamental para a obtenção de resultados promissores do mesmo, porém as informações sobre o sistema e a sensibilização devem ser permanentespara que mais pessoas se envolvam com o processo e para que os que já estão comprometidos se motivem ainda mais.

\section{REFERÊNCIAS}

BARTHOLOMEU, F. J.; AGUIAR, A. L.; FERREIRA, A. P. N. L. Percepção ambiental de colaboradores em relação a práticas ambientais: estudo em uma empresa. 2014.

CAGNIN, C. Fatores Relevantes na Implementação de um Sistema de Gestão Ambiental com Base na Norma ISO 14001. Florianópolis-SC, 2009.
COMPANHIA DE ÁGUA E ESGOTO DO CEARÁ

2016. Disponível em: <http://www.cagece.com.br/ numeros/indice-decobertura> Acesso em: 18 de Jan 2016.

CONCEIÇÃO, A.; COELHO, L. V. T.; TORRES, R. P.; SOUSA, S. P.; NETO, J. S. A importância do sistema de gestão ambiental (sga) - estudo de caso na empresa Grande Rio Honda em Palmas. Palmas: [s.n.], 2011.

CORREIA, C. M. S. Mudanças organizacionais com a implantação do Sistema de Gestão Ambiental:O caso da usina de monlevade. [S.1.], Belo Horizonte, 2006.

CURI, D. Gestão ambiental. In: __ _ [S.1.]: Pearson Prentice Hall, 2012. 154 p. ISBN: 9788564574144.

DEMAGRO, C.; OTT, E. Gestão e contabilidade ambiental em empresas do rio grande do sul. In: IX Congresso Brasileiro de Custos - São Paulo, SP, Brasil. [S.1.: s.n.], 2002.

ESTEVES, V. A.; SAUTTER, K. D.; AZEVEDO, J. A. Percepção do impacto de sistemas de gestão ambiental emhospitais. In: IX ENGEMA - Encontro sobre gestão empresarial e meio ambiente. Curitiba: [s.n.], 2007.

FERNANDES, E. V. G.; SILVA, C. T. B.; LÓTICI, K. M. Avaliação da percepção do sistema de gestão ambiental em uma agroindústria. Gepros: Gestão da Produção, Operações e Sistemas, v. 3, p. 39, 2008.

FERNANDES, R. M. C. A dimensão estratégica da gestão ambiental no setor de saneamento básico. Dissertação (Programa de Pós-Graduação do Curso de Mestrado Profissional em Administração de Empresas do Centro de Estudos Sociais Aplicados) Universidade Estadual do Ceará - UECE, Fortaleza, 2004.

LIMA, J. R. T.; LIRA, T. K. S. A implantação de um sistema de gestão ambiental,baseado na nbr iso 14001:2004 - um estudo de caso de uma empresa prestadora de serviços do polócloroquimico de alagoas. In: II Congresso de Pesquisa e Inovação da Rede Norte Nordeste de Educação Tecnológica, João Pessoa - PB. [S.1.: s.n.], 2007.

MARKONI M. A; LAKATOS, E. M. Fundamentos da metodologia científica. [S.1.], 2003. 
MOREIRA, A. P. Sistema de Gestão Ambiental (sga) e a iso 14001: Um estudo de caso. Dissertação (Mestrado) - Universidade federal de Santa Catarina. Curso de pós-graduação em administração, Florianópolis, 2004.

NBR. Sistemas de Gestão Ambiental: requisito com orientações para uso. Rio de Janeiro, 2004.

OLIVEIRA, M. S.; LEITE, J. S.; LIMA, V. A.; CARVALHO, A. C.; OLIVEIRA, T. G. A.;

PINHEIRO, J. P. S.; LEITE, L. V.; NUNES, L. T. Índice de estado trófico da água do Açude Gavião - CE I CONICBIO / II CONABIO / VI SIMCBIO. Brasil: [s.n.], 2013.

OLIVEIRA, O. J.; PINHEIRO, C. R. M. S.

Implantação de sistemas de gestão ambiental iso 14001: uma contribuição da área de gestão de pessoas. Gestão \& Produção, p. 51-61, 2010.

RIBEIRO, C. S.; AGUIAR, A. O. Treinamento e seu impacto no desempenho do sistema de gestão ambiental: Proposta de modelo de análise. In: Encontro Internacional sobre gestão empresarial e meio ambiente. [S.1.: s.n.].

SOUZA P. C; LIMA, H. M. O. M. M. S. S. A. F. A. Sistema de gestão ambiental: um estudo de caso na companhia de Água e esgoto do ceará. In: CAGECE.XVI Congresso Brasileiro de Custos. Fortaleza-CE: [s.n.].

VICENTE, L. R. Contribuições da certificação ISO 14001 na percepção ambiental em espaço não formal. Dissertação (Mestrado) - Universidade Luterana do Brasil, 2008. 